\title{
Loneliness in Early Adolescence: A Test of the Cognitive Discrepancy Model of Loneliness
}

\author{
Fraser S. Archibald \\ Kwantlen College \\ Kim Bartholomew \\ Simon Fraser University \\ Ronald Marx \\ University of Michigan
}

The cognitive discrepancy model of loneliness postulates that people experience loneliness when they perceive a discrepancy between their actual and desired levels of interpersonal contact. In contrast, a social needs model proposes that loneliness arises from actual deficits in social contact. The incremental value of the cognitive discrepancy model over the social needs model was tested by examining whether cognitive discrepancies predict adolescent loneliness over and above the influence of actual levels of social contact. A total of 217 Grade 10 students participated. Loneliness, actual levels of social contact, and discrepancies from a personally defined ideal standard and a socially defined normative standard of social activity were assessed. The results provided limited support for a cognitive discrepancy model of loneliness. After controlling for actual levels of social activity, actual-ideal and actual-typical discrepancies added only minimally to the prediction of loneliness.

$\mathbf{T}$

he cognitive discrepancy model of loneliness postulates that people experience loneliness when they perceive a discrepancy between their actual and desired levels of interpersonal contact (Perlman \& Peplau, 1982). Actual levels of social involvement are assumed to foster loneliness only to the extent that they differ from one's internal desired standard. Consequently, actual levels of social contact may bear little relationship to how satisfied people are with their social lives. For example, people may be very active socially yet still feel lonely because their levels of social activity do not meet their desired levels of activity.

Although the cognitive model is widely accepted and cited in the loneliness field, few studies have directly tested the relationship between cognitive discrepancies and loneliness (Paloutzian \& Janigan, 1987). Two avenues of research do provide indirect support for the cognitive discrepancy model, however. First, a number of studies have indicated that loneliness does not covary directly with measures of social contact (e.g., Jones, 1981; Sermat, 1980). Second, another line of research has demonstrated the importance of subjective evaluations of one's social relations in mediating loneliness. For instance, Jones and Moore (1987) have documented that satisfaction with one's support network was a better predictor of loneliness than levels of social contact (see also Cutrona \& Peplau, 1979, cited in Cutrona, 1982; Grubrium, 1974).

The cognitive model of loneliness stands in contrast to a social needs perspective that views loneliness as resulting from actual deficits in social contact and intimacy (e.g., Fromm-Reichman, 1959; Sullivan, 1953; Weiss, 1973). According to this perspective, humans possess inherent needs for social contact, needs that may serve adaptive functions (Weiss, 1973). Various social needs or provisions have been identified, including so-

\footnotetext{
Authors' Note: This work was supported by a C. D. Nelson Memorial Scholarship awarded to Fraser Archibald. This article is based, in part, on Fraser Archibald's master's thesis completed at Simon Fraser University under the supervision of Ron Marx. We thank John Hall and the student participants for making this study possible. We also thank Dale Griffin, Nand Kishor, and Ray Koopman for their statistical advice, and three anonymous reviewers for their helpful feedback on earlier drafts of this article. Address correspondence to Kim Bartholomew, Department of Psychology, Simon Fraser University, Burnaby, British Columbia, Canada V5A 1 S6.
}

PSPB, Vol. 21 No. 3, March 1995 296-301

(C) 1995 by the Society for Personality and Social Psychology, Inc. 
cial integration (to provide companionship, a sense of community and protection, social engagement, etc.) and close attachment relationships (to provide emotional security, intimacy, unconditional positive regard, etc.) (Shaver \& Buhrmester, 1983; Weiss, 1973, 1987). When these needs are not met because of the absence or loss of interpersonal relationships, people experience loneliness. Thus a social needs perspective views loneliness as a predictable response to real deficits in relationships.

In summary, whereas the social needs perspective on loneliness emphasizes actual levels of contact, the cognitive discrepancy model emphasizes the perceived discrepancy between actual and desired levels of contact. The cognitive model, although taking into consideration actual levels of contact, proposes that actual levels are only important to the extent that they differ from desired levels. Thus, according to the cognitive model, cognitive discrepancies are expected to predict loneliness over and above the influence of actual levels of social contact. This hypothesis was tested in the present study.

Discrepancies from two kinds of evaluation standards were assessed: an ideal level of social activity and a normative standard of social activity. Ideal levels of social activity reflect the personally defined interpersonal goals to which people aspire. For example, Peplau, Miceli, and Morasch (1982) have suggested that past experiences can lead one "to develop images of the kinds of social interactions and relationships that make us feel satisfied and happy" (p. 136). Normative standards are derived from using one's perceptions of others' social lives as the standard against which to evaluate the adequacy of one's own social life. These standards are thus equivalent to standards based on social comparison.

An adolescent sample was employed because the incidence of loneliness has been found to peak during the adolescent years (Brennan, 1982; Rubenstein \& Shaver, 1982). Moreover, the fact that adolescents appear to be more focused on living up to societal and peer-group expectations than are older individuals suggests that cognitive discrepancies (or at least discrepancies from normative standards) may be particularly salient in this age group (Brennan, 1982). For example, Larson, Csikszentmihalyi, and Graef (1982) have reported that solitary adolescents were more likely than solitary adults to experience elevations in loneliness on weekend evenings. This finding was interpreted as reflecting the tendency of adolescents to compare their own levels of weekend social activity with the presumed weekend activity levels of their peers.

To ensure that the cognitive discrepancies were adequately measured, we also examined the contribution of cognitive discrepancies to the prediction of satisfaction with one's social relationships. A direct judgment of satisfaction should be, almost by definition, related to the discrepancy between actual and desired or ideal social relationships. Therefore, actual-ideal discrepancies, in particular, were expected to be related to judgments of satisfaction over and above the influence of actual levels of activity. If cognitive discrepancies are predictive of satisfaction ratings but not loneliness, then it would be possible to rule out problems with the measurement of cognitive discrepancies as an explanation of null results.

\section{METHOD}

\section{Subjects}

Participating in this study were 217 Grade 10 students from a high school in a middle-class suburban area of Vancouver, Canada. Informed consent was obtained from participants, parents, and school officials. Of 11 sections of a compulsory guidance course, 9 participated in the study, and only one student in a participating class declined to volunteer. The final sample consisted of $99 \%$ of the eligible participants and $67 \%$ of the total population of Grade 10 students in the school.

The sample consisted of 116 males and 101 females. Their ages ranged from 14 to 17 years, and the average age was 15.3 years $(S D=.56)$. The ethnic backgrounds of subjects were as follows: $53 \%$ White, $36 \%$ Asian, $4 \%$ East Indian, and $6 \%$ other.

\section{Procedure}

Participants completed the Social Life Questionnaire (Archibald, 1989) and the revised UCLA Loneliness Scale (Russell, Peplau, \& Cutrona, 1980) in school classrooms during regular 50-minute class periods. Questionnaires were anonymous.

The Social Life Questionnaire (Archibald, 1989) is an inventory that asks students about various aspects of their social relationships. Included are 78 questions that ask students to estimate their own actual and ideal levels of social activity and also the typical student's level of social activity across the domains of social friends, close friends, and special activities (e.g., parties, movies with friends). For example, subjects were asked, "How often on a Friday or Saturday evening (a) do you get together with friends? (b) would you like to get together with friends? and (c) does the typical student [of your sex and grade level] get together with friends?" Answers were scored on 7-point scales. In designing the measure, we tried to be sensitive to how adolescents subjectively think about their levels of social involvement, rather than simply counting the number of social contacts in a day or the minutes spent in each interaction. The measure thus assessed the frequency of periods of contact across the day (i.e., how often one gets together with friends 
before school, at lunch, after school, on weekday evenings, etc.) and the inclusion in special activities.

Seven questions also assessed subjects' satisfaction with their social relationships across the three content domains; these items were standardized and combined into a composite measure of satisfaction (alpha $=.92$ ).

Actual-ideal discrepancy scores were derived by subtracting subjects' estimates of their actual levels of social contact from their ideal levels of social engagement on corresponding items. Actual-typical discrepancies were obtained in a parallel fashion. All items were then converted to $z$ scores, and items were summed separately for each estimate-actual, actual-ideal discrepancies, and actual-typical discrepancies. The reliabilities of each scale, as computed by coefficient alpha, were as follows: actual level of activity (alpha $=.96$ ), actual-ideal discrepancies (alpha $=.94)$, and actual-typical discrepancies $($ alpha $=.96)$.

The revised UCLA Loneliness Scale (Russell et al., 1980 ) is a 20-item unidimensional measure of loneliness. The scale possesses high internal consistency (Russell et al., 1980) and has been used in a number of studies with adolescents (e.g., Schultz \& Moore, 1988; Williams, 1983). In the present study, this scale had an alpha of .89 .

\section{RESULTS}

\section{Descriptive Statistics}

The mean loneliness score was $37.93(S D=10.04)$. This finding was consistent with other research using adolescent and college samples (e.g., Russell et al., 1980; Schultz \& Moore, 1988). The mean loneliness score was $35.57(S D=8.98)$ for the 116 males and $40.49(S D=$ 10.53) for the 101 females.

On average, subjects reported higher ideal levels of activity than actual levels, $t(216)=11.78, p<.001$, and higher estimates of the typical student's level of activity than actual levels, $t(216)=7.01, p<.001$. In fact, more than $80 \%$ of the subjects overestimated the typical student's level of social activity.

Intercorrelations between the loneliness, satisfaction, and social activity measures are shown in Table 1.

\section{Sex Differences}

A gender effect for loneliness was obtained, $F(1,215)=$ 13.83, $p<.001$; females on average scored higher than males. In light of this finding, sex was covaried in all subsequent analyses. No significant sex differences were obtained on the satisfaction or social activity measures.

\section{Prediction of Loneliness}

To examine whether cognitive discrepancies mediated loneliness above and beyond the influence of actual levels of social activity, a series of hierarchical regressions
TABLE 1: Intercorrelations of Social Activity Measures, Loneliness, and Satisfaction

\begin{tabular}{|c|c|c|c|c|}
\hline & $\begin{array}{l}\text { Actual } \\
\text { Activity }\end{array}$ & $\begin{array}{l}\text { Actual-Ideal } \\
\text { Discrepancy }\end{array}$ & $\begin{array}{c}\text { Actual-Typical } \\
\text { Discrepancy }\end{array}$ & Loneliness \\
\hline Actual activity & - & & & \\
\hline $\begin{array}{l}\text { Actual-ideal } \\
\text { discrepancy }\end{array}$ & $-.60^{*}$ & - & & \\
\hline $\begin{array}{r}\text { Actual-typical } \\
\text { discrepancy }\end{array}$ & $-.82 *$ & $.71^{*}$ & - & \\
\hline Loneliness & $-.46^{*}$ & $.35^{*}$ & $.43^{*}$ & - \\
\hline Satisfaction & $.56 *$ & $-.63 *$ & $-.54 *$ & $-.47 *$ \\
\hline
\end{tabular}

NOTE: $N=217$.

$* p<.001$.

was performed. In each case, sex was entered first, followed by actual activity scores. In separate equations, each cognitive discrepancy was then entered, followed by the interaction of actual and discrepancy scores. The two discrepancies were analyzed separately to investigate their relative contributions to predicting loneliness in this population. An interaction term was included in case discrepancies are of greater importance at low or high levels of activity. For instance, it may be that cognitive discrepancies are only significant in understanding loneliness when a minimal level of activity has been achieved. In a final equation, the two discrepancy scores and the two interaction terms were entered in blocks to examine the joint contribution of the two discrepancy measures.

The results of these analyses are displayed in Table 2. Actual activity levels predicted $21 \%$ of the variance in loneliness, and only actual-typical discrepancies separately added a small but significant portion of the variance $(2 \%)$. When the two discrepancy scores were entered together in Step 3 of the equation, the additional variance explained $(2 \%)$ did not reach significance. In no case did the interaction terms add significantly to the regression equation. ${ }^{1}$

\section{Prediction of Satisfaction}

A parallel set of regression analyses was performed predicting satisfaction with social relationships. The results of these analyses are presented in Table 3. Actual activity predicted $31 \%$ of the variance in satisfaction. Actual-ideal discrepancies added $14 \%$ variance, and the actual by actual-ideal interaction term explained a further $1 \%$ variance. Supplementary analyses indicated that actual-ideal discrepancies were more strongly related to satisfaction (controlling for actual scores) at higher levels of actual activity. In contrast, actual-typical discrepancies added only $2 \%$ additional variance to the prediction of satisfaction. In the final equation, the block of discrepancy scores and the block of interaction terms each added significant variance to the regression equation. 
TABLE 2: Hierarchical Regressions of Social Activity Measures on to Loneliness

\begin{tabular}{llc}
\hline Step & $\mathrm{R}^{2}$ & $\mathrm{~F}$ \\
\hline 1 Sex & .06 & $14.31^{* *}$ \\
2 Actual activity & .21 & $62.36^{* *}$ \\
3 Actual-ideal discrepancy & .01 & 3.64 \\
4 Actual by actual-ideal interaction & .00 & .30 \\
3 Actual-typical discrepancy & .02 & $4.91^{*}$ \\
4 Actual by actual-typical interaction & .00 & .01 \\
3 Both discrepancy scores & .02 & 2.91 \\
4 Both interaction terms & .00 & .38 \\
\hline
\end{tabular}

NOTE: $N=217$.

${ }^{*} p<.05 .{ }^{* *} p<.001$.

Although the hierarchical regressions presented above directly tested the hypothesis that discrepancies predict loneliness independent of actual levels of social contact, it could be argued that this approach underestimated the predictive power of cognitive discrepancies. By entering the actual activity variable into the regression equation prior to the discrepancy variable, the shared variance of these two variables was attributed solely to actual activity levels. We therefore conducted two additional regressions, predicting loneliness and satisfaction, in which all of the predictor variables were entered simultaneously into the regression equation.

The results of these analyses are presented in Table 4. The part correlations indicated the unique contribution of each independent variable in the prediction of loneliness or satisfaction, controlling for the contribution of the other independent variables. The results were generally consistent with the hierarchical analyses. Only sex and actual activity levels independently predicted loneliness; not one of the discrepancy or actual-discrepancy interactions contributed unique variance to the prediction equation. In contrast, actual-ideal discrepancies and the interaction between actual activity and actual-typical discrepancies (as well as actual activity levels) contributed unique variance to the prediction of satisfaction.

\section{DISCUSSION}

The results of this study provide only marginal support for the cognitive discrepancy model of loneliness. Discrepancies from both personally defined and socially defined evaluation standards were associated with adolescent loneliness, but when actual levels of activity were controlled, these associations were greatly reduced. Only actual-typical discrepancies remained significant predictors of loneliness, and even in this case, the amount of variance explained was small $(2 \%)$. Moreover, only actual levels of activity contributed unique variance to the prediction of loneliness. In addition, no evidence was
TABLE 3: Hierarchical Regressions of Social Activity Measures on to Satisfaction

\begin{tabular}{lcc}
\hline Step & $\mathrm{R}^{2}$ & $\mathrm{~F}$ \\
\hline 1 Sex & .01 & 1.51 \\
2 Actual activity & .31 & $95.37^{* * *}$ \\
3 Actual-ideal discrepancy & .14 & $53.08^{* * *}$ \\
4 Actual by actual-ideal interaction & .01 & $4.85^{*}$ \\
3 Actual-typical discrepancy & .02 & $6.40^{*}$ \\
4 Actual by actual-typical interaction & .01 & 1.79 \\
3 Both discrepancy scores & .14 & $26.86^{* * *}$ \\
4 Both interaction terms & .03 & $5.33^{* *}$ \\
\hline
\end{tabular}

NOTE: $N=217$

${ }^{*} p<.05 .{ }^{* *} p<.01 . * * * p<.001$.

obtained that discrepancies and actual levels of activity interact in the prediction of loneliness.

Although it is always difficult to interpret the meaning of null or weak results, other findings suggest that these results cannot be explained by problems with the measurement of the discrepancies. High reliabilities were obtained for both discrepancy scores. In addition, discrepancy means indicated that on average, subjects did report significant discrepancies between their actual levels of social activity and both their ideal levels and their perceptions of the typical student's level of activity. Moreover, both forms of discrepancies, and actual-ideal discrepancies in particular, were associated with satisfaction with social relations independent of the effects of level of activity.

These results are particularly noteworthy given that the study was designed to maximize the possibility of finding support for the cognitive discrepancy model of loneliness. An adolescent sample was employed because discrepancies were expected to be especially important in this age group. Item by item, subjects made judgments of their actual and ideal levels of activity and of the typical student's level of activity to ensure their awareness of potential discrepancies. In addition, the loneliness scale was completed immediately after the Social Activities Questionnaire to maximize the salience of discrepancies in making ratings of loneliness.

The operationalization of cognitive discrepancies in this study was limited in scope, however. The social activity measure focused on interactions with close friends and less intimate social friends. The quite strong correlations between social contact with friends and both loneliness and social satisfaction suggest that these social domains are of central importance for this age group. However, future research needs to assess a broader range of social relationships. We did collect information on participants' romantic relationships; but there were so few students who were involved in romantic relationships (only $15 \%$ ) that, not surprisingly, these 
TABLE 4: Simultaneous Regressions of Social Activity Measures Onto Loneliness and Satisfaction

\begin{tabular}{|c|c|c|c|c|}
\hline & \multicolumn{2}{|c|}{ Loneliness } & \multicolumn{2}{|c|}{ Satisfaction } \\
\hline & $\begin{array}{c}\text { Part } \\
\text { Correlation }\end{array}$ & $\mathrm{t}$-test & $\begin{array}{c}\text { Part } \\
\text { Correlation }\end{array}$ & $\mathrm{t}$-test \\
\hline Sex & .25 & $4.31 * *$ & .02 & .44 \\
\hline Actual activity & .16 & $2.80^{*}$ & .20 & $4.00^{* *}$ \\
\hline Actual-ideal discrepancy & .01 & .23 & .26 & $5.29 * *$ \\
\hline Actual-typical discrepancy & .08 & 1.46 & -.03 & .59 \\
\hline $\begin{array}{l}\text { Actual by actual-ideal } \\
\text { interaction }\end{array}$ & .05 & .87 & .00 & .05 \\
\hline $\begin{array}{l}\text { Actual by actual-typical } \\
\text { interaction }\end{array}$ & -.05 & .83 & -.14 & $2.77^{*}$ \\
\hline Multiple R & .54 & & 69 & \\
\hline
\end{tabular}

NOTE: $N=217$

${ }^{*} p<.01 ;{ }^{* *} p<.001$.

variables were weakly related to the outcome variables. Perhaps a more crucial domain for inclusion is family relationships, which continue to be very important for adolescents (Steinberg, 1990).

In addition, questions focused on activity levels and did not assess other aspects of social relations, such as the number of relationships, the density of social networks, or qualitative aspects of relationships (e.g., Cutrona, 1982; Stokes, 1985). In particular, more support for the cognitive model of loneliness would have been obtained if the measurement of discrepancies was expanded to include perceptions of the quality of relationships. However, because loneliness is, at least in part, a measure of the quality of social relationships, such an approach would lead to the difficult issue of discriminant validity between the independent and dependent measures. It also would be difficult to design qualitative measures of ideal social relationships that would be sensitive to individual differences (i.e., that would yield sufficient variability in images of ideal relationships).

This study is also limited by the use of a unidimensional measure of loneliness (the UCLA Loneliness Scale). A number of studies have indicated that loneliness is a multidimensional construct and that different aspects of loneliness may have different etiologies and associated emotional responses (e.g., Rook, 1988; Rubenstein \& Shaver, 1982; Shaver, Furman, \& Buhrmester, 1985). Working within a social needs perspective, Weiss (1973) has argued that a lack or loss of attachment relationships gives rise to emotional loneliness, whereas a lack or loss of a network of friends and associates gives rise to social loneliness. It is unclear how these distinct forms of loneliness may differentially relate to cognitive discrepancies. However, we speculate that cognitive discrepancies in early adolescence will be more predictive of social than emotional loneliness. First, it might be argued that emotional loneliness results directly from the activation of the attachment system (Weiss, 1987) and need not be mediated by conscious cognitive discrepancies (for instance, as is presumably the case in infant attachment relationships). In addition, in the age group studied, parents are likely to continue to be primary attachment figures for a majority of subjects (Hazan \& Zeifman, 1994), suggesting that the peer relations assessed may be more strongly related to social than emotional loneliness (Russell, Cutrona, Rose, \& Yurko, 1984). Nonetheless, it is clearly important to replicate the present results with multidimensional loneliness measures.

It is also important for future research to replicate these findings in other age groups. For example, ideal standards may become more important with increasing age, as individuals develop clearer notions of the ideal quantity and quality of their social relationships.

Although these results do not strongly support a cognitive model of loneliness, they are consistent with the social needs perspective. The important distinction between these two approaches to understanding loneliness was captured by Horowitz (1984) when he asked the question, "Is the problem of loneliness a matter of reality or a problem in the head?" (p. 4). Our results suggest that loneliness, at least as measured in the present study, is a matter of reality. Adolescents' levels of social activity were strongly related to their reported levels of loneliness, and this association largely accounted for the relationship between cognitive discrepancies and loneliness.

In summary, the present study provides little support for the cognitive discrepancy model of loneliness. This study is limited, however, by a unidimensional measure of loneliness and an exclusive focus on the quantitative aspects of peer relationships. On the other hand, these findings are surprising given that the sample and the measurement methods were chosen to optimize the chances of providing evidence for the cognitive model. At the very least, we hope that this initial test of the cognitive discrepancy model will challenge future researchers to examine critically this widely accepted and yet rarely tested theory of loneliness.

\section{NOTE}

1. To address the question of whether close relationships are more important than less intimate relationships in the prediction of loneliness, we also conducted these analyses separately for subscales of the Social Life Questionnaire focusing on close relationships and more general social relationships. The same pattern of results was obtained across both domains.

\section{REFERENCES}

Archibald, F. S. (1989). Cognitive discrepancies in adolescent loneliness: Exploring a dual discrepancy model. Unpublished master's thesis, Simon Fraser University, Burnaby, British Columbia, Canada. 
Brennan, T. (1982). Loneliness in adolescence. In L. A. Peplau \& D. Perlman (Eds.), Loneliness: A sourcebook of current theory, research, and therapy (pp. 269-290). New York: Wiley-Interscience.

Cutrona, C. E. (1982). Transition to college: Loneliness and the process of social adjustment. In L. A. Peplau \& D. Perlman (Eds.), Loneliness. A sourcebook of current theory, research, and therapy (pp. 291-301). New York: Wiley-Interscience.

Fromm-Reichman, F. (1959). Loneliness. Psychiatry, 22, 1-15.

Grubrium, J. F. (1974). Marital desolation and the evaluation of everyday life in old age. Journal of Marriage and the Family, 26, 107-113.

Hazan, C., \& Zeifman, D. (1994). Sex and the psychological tether. In K. Bartholomew \& D. Perlman (Eds.), Advances in personal relationships: Vol. 5. Attachment processes in adulthood. London: Jessica Kingsley.

Horowitz, L. M. (1984). The toll of loneliness: Manifestations, mechanisms, and means of prevention. Washington, DC: National Institute of Mental Health.

Jones, W. H. (1981). Loneliness and social contact. Journal of Social Psychology, 113, 295-296.

Jones, W. H., \& Moore, T. L. (1987). Loneliness and social support. In M. Hojat \& R. Crandall (Eds.), Loneliness: Theory, research, and applications [Special issue]. Journal of Social Behavior and Personality, $2,145-156$.

Larson, R., Csikszentmihalyi, M., \& Graef, R. (1982). Time alone in daily experience: Loneliness or renewal? In L. A. Peplau \& D. Perlman (Eds.), Loneliness: A sourcebook of current theory, research, and therapy (pp. 291-301). New York: Wiley-Interscience.

Paloutzian, R. F., \& Janigan, A. S. (1987). Models and methods in loneliness research: Their status and direction. In M. Hojat \& $\mathrm{R}$. Crandall (Eds.), Loneliness: Theory, research, and applications [Special issue]. Journal of Social Behavior and Personality, 2, 31-36.

Peplau, L. A., Miceli, M., \& Morasch, B. (1982). Loneliness and selfevaluation. In L. A. Peplau \& D. Perlman (Eds.), Loneliness: A sourcebook of current theory, research, and therapy (pp. 135-151). New York: Wiley-Interscience.

Perlman, D., \& Peplau, L. A. (1982). Theoretical approaches to loneliness. In L. A. Peplau \& D. Perlman (Eds.), Loneliness: A sourcebook of current theory, research, and therapy (pp. 123-134). New York: WileyInterscience.

Rook, K. S. (1988). Toward a more differentiated view of loneliness. In S. Duck (Ed.), Handbook of personal relationships (pp. 571-589). New York: Wiley.
Rubenstein, C. A., \& Shaver, P. (1982). The experience of loneliness. In L. A. Peplau \& D. Perlman (Eds.), Loneliness: A sourcebook of current theory, research, and therapy (pp. 269-290). New York: Wiley-Interscience.

Russell, D., Cutrona, C. E., Rose, J., \& Yurko, K. (1984). Social and emotional loneliness: An examination of Weiss's typology of loneliness. Journal of Personality and Social Psychology, 46, 1313-1321.

Russell, D., Peplau, L. A., \& Cutrona, C. E. (1980). The revised UCLA Loneliness Scale: Concurrent and discriminant validity evidence. Journal of Personality and Social Psychology, 39, 472-480.

Schultz, N. R., \& Moore, D. D. (1988). Loneliness: Differences across three age levels. Journal of Social and Personal Relationships, 5, 275-284.

Sermat, V. (1980). Some situational and personality correlates of loneliness. In J. Hertog, J. R. Audy, \& Y. A. Cohen (Eds.), The anatomy of loneliness. New York: International Universities Press.

Shaver, P., \& Buhrmester, D. (1983). Loneliness, sex-role orientation, and group life: A social needs perspective. In P. B. Paulus (Ed.), Basic group processes (pp. 259-288). New York: Springer-Verlag.

Shaver, P., Furman, W., \& Buhrmester, D. (1985). Transition to college: Network changes, social skills, and loneliness. In S. Duck \& D. Perlman (Eds.), Understanding personal relationships: An interdisciplinary approach (pp. 193-219). London: Sage.

Steinberg, L. (1990). Autonomy, conflict, and harmony in the family relationship. In S. S. Feldman \& G. R. Elliot (Eds.), At the threshold: The developing adolescent (pp. 255-275). Cambridge, MA: Harvard University Press.

Stokes, J. P. (1985). The relation of social network and individual difference variables to loneliness. Journal of Personality and Social Psychology, 48, 981-990.

Sullivan, H. S. (1953). The interpersonal theory of psychiatry. New York: Norton.

Weiss, R. S. (1973). Lomeliness: The experience of emotional and social loneliness. Cambridge, MA: MIT Press.

Weiss, R. S. (1987). Reflections of the present state of loneliness research. In M. Hojat \& R. Crandall (Eds.), Loneliness: Theory, research, and applications [Special issue]. Journal of Social Behavior and Personality, 2, 1-16.

Williams, E. G. (1983). Adolescent loneliness. Adolescence, 18, 51-59.

Received July 12, 1991

Revision received July 19, 1993

Accepted July 21, 1993 